DOI: 10.12957/demetra.2018.30779

\title{
A prática reflexiva como recurso na gestão dos restaurantes universitários terceirizados
}

\section{Reflective practice as a resource in the management of outsourced university restaurants}

Carla lonara Xavier da Silveira Cardoso'

Marcos Gilson Gomes Feitosa'

Dinara Leslye Macedo e Silva Calazans²

1 Universidade Federal de Pernambuco, Centro de Ciências Sociais Aplicadas, Departamento de Administração. Recife, PE, Brasil.

${ }^{2}$ Universidade Federal do Rio Grande do Norte, Faculdade de Ciências da Saúde do Trairi, Curso de Nutrição. Santa Cruz, RN, Brasil.

Correspondência / Correspondence Carla lonara Xavier da Silveira Cardoso E-mail: carla.ixscardoso@ufpe.br

\section{Resumo}

Objetivo: O objetivo geral desta pesquisa foi investigar como a prática reflexiva pode influenciar na aprendizagem organizacional de serviços de alimentação, a partir da identificação das experiências profissionais de gestores e fiscais de contrato, no contexto dos restaurantes universitários terceirizados de instituições públicas de ensino superior. Metodologia: A estratégia adotada para atingir os objetivos seguiu uma abordagem qualitativa, a partir da técnica do estudo de caso. Os sujeitos de pesquisa foram gestores e fiscais de dois restaurantes universitários pertencentes a duas instituições públicas de ensino superior, localizadas no Nordeste brasileiro, com serviços de alimentação terceirizados. A coleta de dados foi desenvolvida por meio de entrevistas com abordagem direta e roteiro semiestruturado e análise documental, com consulta a documentos internos. As categorias de análise foram definidas a priori, baseadas nas dimensões propostas por Schön para análise da prática reflexiva: o processo de conhecer-na-ação, as dificuldades no âmbito da prática profissional e a articulação prática reflexiva à prática profissional. $\mathrm{O}$ tratamento dos dados se deu através da análise pragmática da linguagem de acordo com Mattos, centrado no significado semântico-pragmático da conversação. Resultados e Discussão: A gestão dos RUs terceirizados ocorre na prática profissional durante o processo de conhecer-naação, especialmente dos nutricionistas, em que as dificuldades, sobretudo na gestão da infraestrutura e de pessoas, influenciam diretamente na gestão dos contratos. É através da reflexão que eles constroem os significados da teoria acerca de sua própria prática, favorecendo a tomada de decisão mais satisfatória. Conclusão: A 
prática reflexiva desponta como propulsor do desenvolvimento de habilidades gerenciais e políticas na implementação de decisões, propiciando a aprendizagem organizacional.

Palavras-chave: Aprendizagem. Prática Profissional. Alimentação Coletiva. Organização e Administração.

\section{Abstract}

Objective: The general objective of this study was to investigate how the reflective practice may influence the organizational learning of food services from the identification of professional experiences of managers and contract inspectors, in the context of outsourced university restaurants of public higher education institutions. Methods: The strategy adopted to achieve the objectives used a qualitative approach based on the case study technique. The research subjects were managers and contract inspectors of two university restaurants belonging to two public higher education institutions, located in the Brazilian Northeast, with outsourced food services. Data collection was developed through semi-structured face-to-face interviews and documental analysis, assessing internal documents. The categories of analysis were previously defined, based on the dimensions proposed by Schön for analysis of reflective practice: the process of knowingin-action, the difficulties in the scope of professional practice and the reflective practical articulation for the professional practice. Data treatment was conducted through the pragmatic analysis of language according to Mattos, centered on the semanticpragmatic meaning of conversation. Results and Discussion: The management of outsourced university restaurants takes place in the professional practice during the process of knowing-inaction, especially of nutritionists, in which difficulties, mainly in the management of people and infrastructure, directly influence the management of contracts. It is through reflection that they build the meanings of the theory on their own practice, favoring the decision-making process. Conclusion: The reflective practice emerges as a driving force for development of managerial and political skills in the implementation of decisions, providing organizational learning.

Keywords: Learning. Professional Practice. Food Service. Organization and Administration. 


\section{Introdução}

O gerenciamento dos serviços de alimentação é complexo, exercido sob pressão temporal e apresenta uma série de riscos - ocupacionais, ambientais e higiênico-sanitários -, que podem afetar tanto a saúde do trabalhador, como a qualidade de ingredientes e processos, impactando na saúde do consumidor. Para tanto, torna-se imprescindível controlar os processos técnicos específicos do trabalho, como o alcance dos objetivos nutricionais, além de uma administração efetiva, de forma a conciliar os aspectos econômicos e sociais do serviço. Destaca-se o aspecto social devido ao foco no indivíduo, tanto aquele que está envolvido com a produção e distribuição da refeição, como o consumidor final. ${ }^{1}$

Observam-se também fatores que interferem diretamente na gestão dos serviços de alimentação, como as dificuldades de organização e processos, alto custo, controle de qualidade, atendimento às legislações e normas, além da falta de preparo suficiente dos gestores para a função administrativa. ${ }^{2}$ No processo dinâmico sobre os diversos aspectos do gerenciamento de serviços de alimentação, são verificadas limitações na ação profissional dos gestores, ${ }^{3}$ que acabam não somente tendo que executar, mas agir com destreza nas situações imprevistas. Destaca-se, então, a necessidade da instrumentalização em saberes e capacidades e o desenvolvimento das competências gerenciais. ${ }^{2,3}$

Nas universidades, os serviços de alimentação são representados pelos restaurantes universitários (RUs), onde a alimentação é eixo estratégico da assistência estudantil, através do PNAES (Programa Nacional de Assistência Estudantil). ${ }^{4}$ O RU se destaca como um dos mais importantes instrumentos para a permanência dos estudantes nos campi. Os RUs apresentam uma enorme variação na oferta da alimentação e nos aspectos relacionados a organização e gestão, sendo reflexo de recursos físicos e financeiros de cada instituição. Quanto ao tipo de gestão, acompanham uma tendência nacional, onde vivenciam um momento de transição entre o serviço próprio e a terceirização, tendo em vista as políticas públicas do governo federal. No contexto dos RUs das universidades brasileiras, grande parte desses gestores é nutricionista, os quais foram investidos dessa competência, sobretudo após a implementação da Lei no 8.234, de 17 de setembro de 1991, quando o "planejamento, organização, direção, supervisão e avaliação de serviços de alimentação e nutrição" se tornaram atividade privativa do nutricionista. ${ }^{5}$

Todavia, a formação do nutricionista, geralmente focada no modelo biomédico, não o prepara suficientemente para o desafio da administração e apresenta lacunas nas competências gerenciais. Considerada uma tarefa complexa, com seus métodos e técnicas próprias, constata-se a nítida dificuldade de associar os conteúdos das teorias administrativas à sua prática profissional. ${ }^{6} \mathrm{Um}$ serviço de alimentação tem o objetivo de elaborar e servir refeições adequadas sob diversos aspectos técnicos, como as questões nutricionais e sanitárias, por exemplo, sem exceder, entretanto, os recursos financeiros previamente estabelecidos para este fim pela empresa. Tanto o gerenciamento dos custos como a alocação dos recursos financeiros em uma UAN são 
influenciados pelos objetivos e pela origem desses recursos: as organizações privadas buscam a redução dos custos, e as públicas, sua otimização., 1,2,7,

O nutricionista gestor requer capacidade de adaptação e educação contínua através da habilidade de saber aprender, passando a contemplar a complexidade e a inter-relação entre conhecimentos, saberes e prática. ${ }^{9}$ Contudo, diante do cenário contemporâneo de rápidas e intensas mudanças, os gestores também precisam adequar sua prática, que passa a exigir novas habilidades para melhor atender às demandas da gestão. Neste sentido, os profissionais vêm adquirindo aprendizado que permite ir além do paradigma positivista e da "racionalidade técnica", a partir da experiência profissional. ${ }^{10}$ Isso viabiliza a revisão de pressupostos já estabelecidos e expande as possibilidades do aprendizado contínuo.

A prática reflexiva - bastante difundida na educação - vem ganhando interesse recentemente no ambiente organizacional, ${ }_{11,12}$ que envolve o aprendizado a partir da reflexão (experiência-ação) antes, durante e depois da ação - nos campos onde envolve incertezas, surpresas, mudanças constantes e relações de causa e efeito complexas - como melhoria da atuação profissional. ${ }^{10}$

Não há um debate robusto e consistente na literatura acerca das práticas reflexivas dos gestores na gestão de serviços de alimentação, nem na gestão dos restaurantes universitários. A literatura aborda o serviço de alimentação como uma organização, porém numa perspectiva restrita do modelo organizacional baseado na estrutura hierárquica e na divisão do trabalho; pouca atenção tem sido dada às questões reflexivas das práticas profissionais dos gestores. Nos últimos anos, os autores vêm dando ênfase à gestão de pessoas dentro dos serviços de alimentação, sugerindo o desenvolvimento de habilidades e competências requeridas para gestão. ${ }^{13}$

Nota-se a ação como um processo principal; não obstante, a ação é frequente durante todo o processo de reflexão, sendo que a reflexão sobre a reflexão na ação resulta em significados mais profundos, permitindo a reorientação do processo durante a ação, bem como sua reinterpretação em ações futuras. ${ }^{9,10}$

Destarte, o que diferencia a reflexão-na-ação de outros métodos de reflexão é sua imediata ignificação para ação. O conhecer-na-ação refere-se aos tipos de conhecimento que são expressos nas ações ditas inteligentes, publicamente observáveis - $\mathrm{o}$ ato de conhecer está na ação (sequência de operações e procedimentos que compõem a "teoria").

A forma dialética de reflexão, da proposta de Schön, ${ }^{10}$ para a formação e desenvolvimento de profissionais, parte da importância de se adotar uma nova postura para a prática reflexiva (pautada na premissa do aprender na ação ou aprender fazendo). O profissional desenvolverá as competências e habilidades, a fim de identificar e intervir nas zonas indeterminadas da prática no momento que os elementos inesperados surgirem nas atividades profissionais. ${ }^{14}$ 
É o aprendizado a partir da experiência, tendo como principal ferramenta a reflexão durante a atuação diária do profissional. O processo de reflexão envolve intencionalidade, e o profissional consciencioso examina sua performance, procurando ações de melhoria.

Assim, tendo em vista que a experiência no ambiente organizacional é uma das principais formas de aprendizado e que a prática reflexiva maximiza o aprendizado a partir da experiência, dando relevância ao "profissional reflexivo", este estudo se propõe a discutir como essa prática, em suas diversas formas, pode contribuir para que as dificuldades existentes na atuação do profissional, enquanto gestor, sejam preenchidas, utilizando como cenário a gestão de restaurantes universitários públicos federais no contexto da terceirização.

\section{Metodologia}

O escopo deste estudo está na identificação das dificuldades de gestão de serviços de alimentação expressas através das práticas profissionais dos gestores e fiscais, tendo como parâmetro de análise a prática reflexiva no âmbito da gestão restaurantes universitários (RUs) terceirizados. Os RUs de instituições de ensino superior (IES) públicos de Pernambuco foram selecionados para a pesquisa por conveniência em relação ao acesso e autorização para o estudo, sendo critérios de inclusão: possuírem as mesmas características organizacionais (serviço de produção e distribuição de refeições, terceirizado - pressupõe-se a terceirização como elemento que impõe complexidade à gestão) e possuir grande porte (produzem e distribuem mais de 2.000 refeições) - indicando a presença de nutricionistas em diferentes níveis gerenciais (estratégico, tático e operacional), o que aumenta a credibilidade e o grau de confiança dos resultados. Para efeito do estudo, foram chamados de Unidade A e Unidade B. Posteriormente, foram conduzidas as entrevistas com os gestores desses RUs.

Para o levantamento dos dados, foram realizadas duas etapas: a primeira consistiu em entrevistas em profundidade com os gestores dos RUs, optando-se pelo contato face a face com o entrevistado, buscando uma comunicação extensa e detalhada. As entrevistas foram realizadas individualmente e gravadas. Para a seleção dos entrevistados, houve intencionalidade devido aos critérios de inclusão utilizados para seleção dos gestores participantes da pesquisa: desenvolver atividades de gestão e/ ou fiscalização dos contratos de produção e distribuição de refeições (diretores, gestores e fiscais de contratos e responsáveis técnicos no âmbito dos RUs do estudo nos diferentes níveis gerenciais e possuir vínculo com a contratante (IFES) ou com a empresa contratada (empresa privada terceirizada prestadora de serviço aos RUs). Considerando-se o potencial de contribuição de suas práticas para o estudo, foram convidados a participar da pesquisa dois ex-gestores dos RUs, que 
deixaram os cargos recentemente e foram responsáveis pela elaboração dos termos de referência ${ }^{\mathrm{a}}$ (documento que gerou o contrato ${ }^{b}$ - quando da terceirização - e implantação dos serviços atuais, tendo contribuído com suas experiências também em relação àquelas realidades. Deste modo, participaram da pesquisa 11 gestores: dois gestores (atuais) de contrato (representantes de cada IES), um fiscal de contrato, dois auxiliares de fiscal, dois ex-gestores (01 de cada IES) e quatro nutricionistas responsáveis técnicos das contratadas.

O roteiro de entrevista teve por base a Mandala de Categorização (figura 1), que foi elaborada tendo em vista o referencial teórico e os objetivos de pesquisa. Para cada objetivo, derivado das dimensões que envolvem a prática reflexiva integrada à gestão em alimentação coletiva -área onde se insere a pesquisa no contexto da gestão dos RUs -, foram definidas as variáveis de pesquisa, que subdivididas em temas originaram as categorias de análise. Cada categoria originou uma questão do roteiro de entrevista. Assim, a mandala representa o grupo de perguntas, com seus respectivos temas e variáveis, isto é, no campo dos objetivos há a informação sobre a relação com outras categorias para atingir o caráter integrativo da pesquisa.

Para o tratamento das respostas das entrevistas, foi utilizada a análise pragmática da linguagem ${ }^{15}$ para explicar o significado semântico-pragmático da conversação. A ênfase foi dada aos significados do contexto, pressupostos ou implicados em cada resposta ou emergentes da interação das respostas, sendo realizada em cinco fases:

- Fase 1: Recuperação - em sentido amplo do momento da fala, incluiu a transcrição completa das entrevistas adicionando anotações relevantes;

- Fase 2: Análise do significado pragmático da conversação - constituída da análise básica (em duas "demãos" de leitura e audiência do texto) com extração do "significado nuclear da resposta", os "significados incidentes" e "as suposições implícitas a respeito do contexto";

- Fase 3: Validação - para firmação do relato em seu aspecto semântico; mencionando-se acontecimentos relatados pelo entrevistado e ratificando-se a informação por meio dos registros e documentos;

- Fase 4: Montagem da consolidação das falas, reunindo relatos, opiniões e atitudes dos entrevistados, com destaque para os significados nucleares das respostas;

- Fase 5: Análise de conjuntos - observando o surgimento das "observações conclusivas", que nada mais são que os resultados gerais da análise.

a Serviço Público Federal. Universidade Federal Rural de Pernambuco. Pró-Reitoria de Administração. Termo de contrato de prestação de serviços n¹5/2014. Consultado em 06 de junho de 2016.

b Serviço Público Federal. Universidade Federal de Pernambuco. Pró-Reitoria de Gestão Administrativa. Diretoria de Licitações e Contratos. Contrato n³2/2014. Consultado em 06 de junho de 2016. 


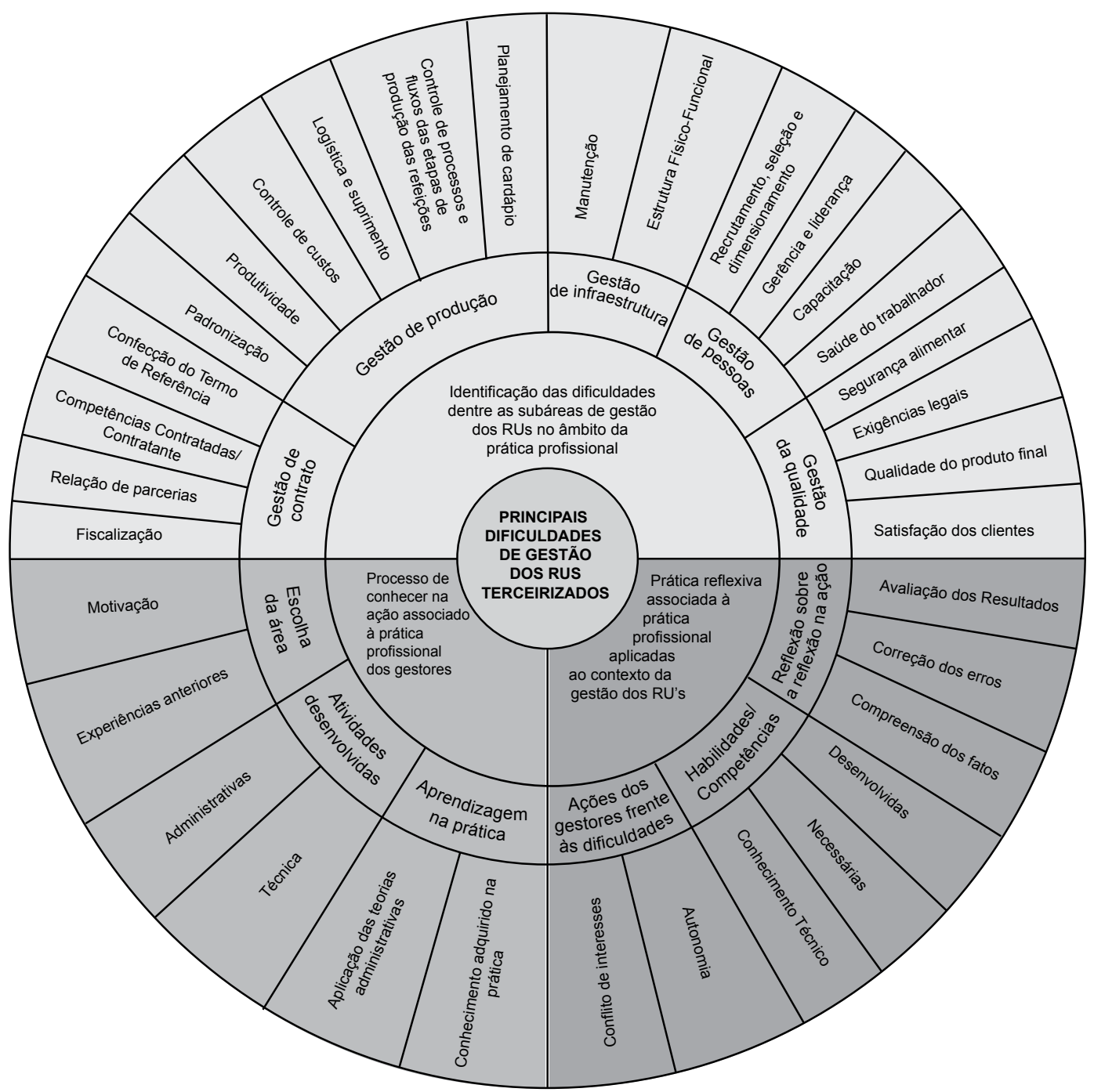

Figura 1. Mandala de categorização das variáveis.

Fonte: autoria própria, 2016.

A segunda etapa foi constituída da análise dos contratos, sobretudo os termos de referência anexos dos mesmos - onde estão detalhados os aspectos que devem ser cumpridos pelas partes e as ações decorrentes -, dos registros de notificações e processos, com o objetivo de descrever os tipos e os conteúdos dos problemas e, principalmente, analisar se há características implícitas da prática reflexiva durante e/ou após a ação dos gestores, utilizando-se as mesmas dimensões descritas na Mandala de Categorização. 
Após a análise das entrevistas e da análise dos contratos, foram identificadas as dificuldades de gestão dos RUs e como estas podem ser minimizadas através da prática reflexiva dos gestores incorporada na sua prática profissional, com a finalidade de aprimoramento e melhoria da gestão dos RUs.

A pesquisa foi aprovada pelo Comitê de Ética em Pesquisa (CEP) da Universidade Federal de Pernambuco (UFPE) mediante parecer n ${ }^{\circ}$ 1.571.608 e CAAE: 55561416.6.0000.5208. As entrevistas ocorreram nos respectivos RUs das IES, em ambiente reservado. A permissão para as entrevistas com os gestores foi consubstanciada com a assinatura prévia do TCLE (Termo de Consentimento Livre e Esclarecido).

\section{Resultados e Discussão}

\section{0 processo de conhecer-na-ação}

O processo de conhecer-na-ação, relacionado à prática profissional dos gestores dos RUs, se inicia quando estes chegaram aos serviços de alimentação e, posteriormente, pelas atividades desenvolvidas, permeadas pela aprendizagem na prática.

A maioria dos gestores dos RUs não escolheram suas funções, eles foram escolhidos, ou por "convite" ou por necessidade (primeira oportunidade de emprego) e por questão de afinidade permanecem na atividade. Somado a essa questão, evidencia-se o fato de as funções de coordenações e diretorias terem sido ocupados por profissionais com cargo de docência. ${ }^{16,17}$ Nas universidades, os gestores têm uma característica peculiar, que os distingue dos gestores de organizações privadas e algumas públicas. Naquelas, os gestores são os próprios professores que, além de atuarem como pesquisadores, exercem também funções gerenciais. ${ }^{17}$

Outra característica é que eles, em geral, continuam atuando como docentes e pesquisadores, mesmo dedicando menos tempo a essas atividades. Naqueles cargos em que há necessidade de maior empenho, pode acontecer de, provisoriamente, o gestor dedicar-se exclusivamente à gestão ${ }^{17}$. Isso é mais comum nos cargos de alta gerência, ou seja, nas pró-reitorias, na chefia de gabinete, na vice-reitoria e na reitoria.

No caso dos RUs, órgãos que funcionam como atividade-meio na universidade, geralmente não há treinamento/ capacitação para o exercício da função gerencial, e o aprendizado acontece "na prática”. Os docentes (não necessariamente nutricionistas), os nutricionistas ou os nutricionistas docentes - que dada a formação generalista do profissional, poderia vir de qualquer área de atuação, nem sempre da área de alimentação coletiva - nos primeiros meses de gestão ainda estão aprendendo suas funções e se inteirando dos procedimentos e práticas gerenciais universitárias. 
E no caso de terceirização dos serviços, precisam se certificar, ainda, das legislações próprias e procedimentos da condução de um contrato público administrativo.

Daí emerge o "talento artístico profissional", que é a performance habilidosa que esses profissionais demonstram nas situações incertas e conflituosas. ${ }^{10}$ Destaca-se também o conhecimento tácito que cada um carrega no saber fazer na prática o seu trabalho, de acordo com suas experiências anteriores, o que se traduz na segurança durante o exercício profissional. Essa segurança, segundo os gestores dos RUs, se solidifica com a prática e a experiência, em que são evidenciados os conhecimentos teóricos, não deixando de ser importantes.

Em contrapartida, alguns gestores afirmaram que somente com a aplicação da teoria, da racionalidade técnica, do conhecimento sistemático, de preferência o científico, o profissional consegue êxito, e que isto está mais relacionado com o que o profissional deseja para sua carreira. Ou seja, sua motivação/ ambição é que o impulsiona a solucionar problemas através da racionalidade técnica. Sublinha-se que esses gestores possuem um alto nível de domínio da teoria, devido aos muitos anos de docência.

Outro ponto de relevância no estudo foi que os gestores defenderam a diferença que observam depois que estão na prática profissional, referida principalmente à aquisição de experiências e saberes relacionados à gestão de pessoas e gestão financeira. Estudos com esse público de gestores de serviços de alimentação identificaram que estão em busca de troca de experiências na área de gestão de pessoas, para transpor o conhecimento literário, o que confirma que esse conhecimento é teórico e distante da realidade do que se pratica. ${ }^{7}$

Quanto à aprendizagem-na-ação, constata-se que a aprendizagem adquirida na prática se sobrepõe às teorias administrativas aplicadas a serviços de alimentação. Apesar de os gestores considerarem importante o conhecimento das teorias administrativas e destacarem a Teoria Clássica, que expõe os princípios administrativos, eles são "atropelados" pela pesada rotina de operações, e ao longo do exercício profissional, se curvam a alguns momentos de frustração pelo não alcance de objetivos e metas. A aprendizagem na prática se manifesta diante da complexidade dos serviços e a rotina de operações que integram a funcionalidade como um todo de uma empresa do segmento de alimentação. ${ }^{16,18}$ Enfim os gestores, de forma contundente, admitiram que é a experiência que ensina.

E essa aprendizagem, notadamente, se dá no âmbito de gestão de pessoas, em especial na valorização dos recursos humanos. Isso se impõe como um grande desafio, pois o trabalho depende diretamente das pessoas - se a equipe não se sentir valorizada, se não assumir o compromisso com o resultado, concebendo-se parte deste, o produto final não sai a contento.

Na gestão do contrato também ocorre aprendizagem na ação, enquanto fiscalização do serviço terceirizado pelos gestores das contratantes, reunindo características de tangibilidade, que são as 
refeições, mas também de intangibilidade, tendo em vista a preocupação de satisfazer o cliente, que envolve, além do atendimento com qualidade, ambiente confortável, cortesia, presteza e segurança. ${ }^{2}$ A fiscalização também traz consigo o atendimento integral das exigências legais, contratuais e as cobranças de auditorias. São conceitos e leis com que os gestores vão se familiarizando no decorrer da vigência contratual.

Por último, mas tão importante quanto, os gestores aprenderam na prática que o RU detém uma singularidade, que não é conhecida pelos gestores anteriormente e que apenas é desvendada no decorrer da gestão. É sobre a gestão política e participativa, proveniente tanto dos alunos, que exigem a participação dos seus representantes na tomada de decisões, quanto da representação superior da universidade, que interfere diretamente nas decisões dos gestores.

Esse traquejo dos gestores demanda esforços e artimanhas para o atendimento nas duas esferas, e exige do gestor a atuação política, como agente de mudança, comunicador, gerenciador de conflitos e de diversidade, e ainda como construtor de relações com a sociedade. ${ }^{16,17} \mathrm{O}$ RU é um local de inclusão social, em que muitos alunos possuem vulnerabilidade socioeconômica e dizem ser "dono do negócio", termo utilizado por um dos gestores entrevistados, além de fazer parte de uma política de assistência estudantil.

Diante disso, muitas vezes a gestão de problemas relacionados a preço, qualidade do serviço prestado, além daqueles relacionados à infraestrutura, torna-se uma objeção para a gestão do RU, considerando as dificuldades de relacionamento, comunicação e poder de decisão dos gestores dentre todos esses atores.

\section{Identificação das dificuldades nas subáreas de gestão dos RUs no âmbito da prática profissional}

Ficou evidenciado na pesquisa que os maiores obstáculos no âmbito da prática profissional dos gestores nos RUs estão: na gestão da infraestrutura, gestão de pessoas e na gestão do contrato, a partir dos destaques nos relatos.

Quanto à estrutura física, os gestores argumentaram que esta é deficiente em vários aspectos (tamanho, estrutura antiga etc.) e isto compromete todas as outras subáreas da gestão dos RUs, dentre as quais a gestão de pessoas (saúde do trabalhador, dimensionamento de pessoal e ergonomia); a gestão da produção (logística e suprimento, cumprimento do cardápio); a gestão da qualidade das refeições (favorece o cruzamento dos fluxos dos processos) e a gestão do contrato (a contratada não consegue cumprir todas as exigências legais). Outro problema está na ausência e/ou insuficiência na manutenção da infraestrutura como um todo, parte física e funcional (equipamentos).

O problema da estrutura física dos RUs não é um problema pontual dos RUs do Recife-PE, mas se estende quase em sua totalidade nos RUs brasileiros, e se agravou após o programa de 
Reestruturação e Expansão das Universidades Federais (REUNI), em 2008, conforme discutido no Fórum Nacional de Pró-reitores de Assuntos Comunitários e Estudantis (FONAPRACE). ${ }^{19}$ Ocorre tanto o subdimensionamento da estrutura, nas áreas de recepção, produção, armazenamento dos gêneros alimentícios e refeitório (onde mais se revela o problema nas grandes filas dos usuários), quanto na idade de construção dos prédios (como um dos RUs desta pesquisa, que segundo um gestor, disse ter sido construído em 1950) e ausência de manutenções prediais.

Como solução para esse problema, os gestores dos RUs citaram, além da sensibilização da alta gestão da universidade, o desenvolvimento de um planejamento estratégico a longo prazo para restruturação e ampliação dos RUs, incluindo-se a descentralização (criação de vários RUs em um mesmo campus) e a intersetorialização entre assistência estudantil e os órgãos de planejamento e execução das IES, principalmente relacionados à infraestrutura do campus, com o objetivo de construir um orçamento unificado e atender a demanda e expectativa dos usuários..$^{20,21}$

Outra vez, o assunto de gestão de pessoas vem à tona como dificuldade de gestão, um fator limitante para o desenvolvimento do trabalho nos RUs. Os questionamentos dos gestores giram em torno de como chefiar uma equipe, como se comportar em situações de conflito interpessoal, como orientar os funcionários nos procedimentos técnicos e comportamentais e como atuar para garantir melhores resultados.

Além do mais, reclamam do baixo nível de formação dos funcionários; alta rotatividade; que as empresas (terceirizadas) não investem em capacitação adequada; quantitativo insuficiente de funcionários; falta reconhecimento do funcionário por parte da empresa, inclusive questões relacionadas ao cumprimento dos direitos trabalhistas. Essa evidência oportuniza refletir sobre a precarização do trabalho como reestruturação produtiva do capital, que, segundo defensores, é uma ferramenta de resultados inquestionáveis para reduzir custos e aumentar a produtividade..$^{2,22}$ Ressalvados os ganhos sobre os óbices legais que orientam e, em certa medida, protegem o trabalhador nessa jurisprudência, vê-se a exploração do trabalho do homem pelo próprio homem, através da precarização das condições de trabalho ${ }^{22}$.

É válido lembrar, também, que ocorreu a extinção dos cargos públicos de cozinheiros e ajudantes de cozinha, com substituição por mão de obra prestadora de serviços não especializada e consequente queda na qualificação do quadro funcional neste setor operacional. Isso ficou mais evidente com a aposentadoria dos servidores públicos e a não realização de mais concursos públicos para esses cargos.

Quando consultada a literatura específica da área, verifica-se que não há uma fórmula pronta para gerenciar pessoas, mas que existem estilos de gestão que propiciam o envolvimento da equipe com o trabalho. ${ }^{6}$ A conduta adequada dependerá das circunstâncias e da própria subjetividade do ambiente; o gestor pode assumir diversos papéis que a situação exigir, brando ou enérgico, 
participativo ou distante, compartilhando em alguns momentos e em outros convencendo, em certos momentos delegando e em outros determinando.

No tocante à gestão dos contratos, as dificuldades foram referenciadas sobretudo pelos gestores das contratantes, quanto ao detalhamento insuficiente da composição do cardápio, em termos de qualidade e quantidade, e a falta de padronização dos serviços. Eles atribuem estes ao termo de referência (TR) - documento técnico que serve de base para a elaboração do contrato, que afirmam ser incompleto. Como a maioria já assumiu a função de fiscais durante a vigência do contrato, observam várias lacunas que poderiam ser corrigidas no momento da confecção do TR. Todos falaram em ajustes de contrato, com exceção dos que fizeram parte da confecção dos termos. Apesar de não terem o conhecimento na íntegra para sua elaboração, destacam ser imprescindível a participação do gestor que vai atuar nesse processo, em sua construção.

Todavia, a elaboração de um TR não é uma tarefa simples; ao contrário, é um valioso exercício de planejamento, sua concepção é complexa, exige tempo e deve ser resultado de um esforço multidisciplinar, incluindo técnicos especialistas que dominem as especificidades do objeto contratado. ${ }^{2} \mathrm{O}$ TR será o referencial para o edital e, consequentemente, para o processo licitatório. Uma planilha detalhada que contemple o custo e a formação do preço do serviço, bem como a qualidade do produto que se deseja, é um fator indispensável e relevante. Durante esse processo de contratação, as empresas acabam se preocupando mais com o custo do que com a qualidade, no intuito de saírem vencedoras do certame.

Daí a relevância da confecção do TR para a contratação de serviços de alimentação. São vários detalhes que apenas são observados durante a prestação do serviço. Mas há um ponto em que a literatura e os gestores convergem: o objeto do contrato para serviços na área de alimentação coletiva deve ser bem detalhado, principalmente em relação à composição do cardápio (frequência de preparações, qualidade da matéria prima etc.), além de contemplar os custos e os tipos de controle, deveres da contratada e contratante e informações referentes à fiscalização e ao gerenciamento do contrato, baseados sempre na legislação vigente. Também é importante mencionar a solicitação de documentação relativa à qualificação técnica da contratada, com o objetivo de apresentar requisitos operacionais e profissionais para a perfeita execução do serviço. ${ }^{2}$

\section{A prática reflexiva articulada à prática profissional no contexto da gestão dos RUs}

A prática reflexiva dos gestores foi descrita em conjunto com a identificação das principais dificuldades de gestão dos RUs, através da reflexão sobre a reflexão-na-ação (quadro 1). À medida que foram enumerando as dificuldades, os gestores refletiram sobre seus próprios processos na prática profissional e compararam suas experiências de aprendizagem real com as teorias formais. 
Quadro 1. A prática reflexiva articulada à prática profissional no contexto da gestão dos RUs.

\begin{tabular}{|c|c|c|}
\hline $\begin{array}{c}\text { Ações dos gestores frente } \\
\text { às dificuldades }\end{array}$ & Habilidades/ Competências & $\begin{array}{c}\text { Reflexão sobre a reflexão } \\
\text { na ação }\end{array}$ \\
\hline Adaptação à realidade & Nutricionista (Lei n8.234) & Compreensão dos fatos \\
\hline $\begin{array}{l}\text { Registro de ocorrências- } \\
\text { abertura de processos }\end{array}$ & $\begin{array}{l}\text { Conhecimentos técnicos; } \\
\text { administrativos e legais }\end{array}$ & Correção dos erros \\
\hline Comunicação efetiva & Experiência na prática & Avaliação dos resultados \\
\hline $\begin{array}{l}\text { Capacitação de pessoal; } \\
\text { definição de processos }\end{array}$ & $\begin{array}{l}\text { Liderança, trato nas relações } \\
\text { humanas }\end{array}$ & \multirow{3}{*}{$\begin{array}{l}\text { Situações imprevistas: } \\
\text { oscilações no quantitativo } \\
\text { Acidentes de trabalho } \\
\text { Desvio de produtos, direitos } \\
\text { trabalhistas etc. }\end{array}$} \\
\hline Trabalho intersetorial & Comunicação & \\
\hline Valorização da equipe & $\begin{array}{l}\text { Capacidade de planejar, } \\
\text { decidir e gerenciar crises }\end{array}$ & \\
\hline Relação de parcerias & Negociação & Ação política \\
\hline
\end{tabular}

Fonte: Dados da pesquisa, 2016

No contexto da gestão dos RUs, as ações dos gestores frente às dificuldades são concebidas por sua própria prática, levando em consideração a adaptação à realidade de trabalho, muitas vezes um ambiente hostil, especialmente quanto à estrutura física; e a ponderação diante de algumas dificuldades, desde que não comprometam a segurança alimentar; e também quanto aexigências contratuais. Igualmente, a autonomia é limitada, o que muitas vezes impede a total resolução de determinados problemas.

O ambiente na produção de refeições mostra-se hostil, tendo as características frequentes: ritmo de trabalho intenso, número elevado de tarefas diferentes, de acordo com as necessidades do momento; condições de trabalho inadequadas, equipamentos subdimensionados, quebrados, ambientes quentes etc. ${ }^{23}$ Porém os gestores não devem se adaptar a essa situação, mas procurar analisar e superar os desafios. É importante os gestores reagirem, desenvolverem a criatividade e saberem tomar decisões que atendam aos desafios desse cenário, intensificadas pela precarização do trabalho na terceirização, superando situações de adversidade e se diferenciando com reflexo positivo.

A reflexão-na-ação dos gestores em relação à gestão dos contratos é relacionada ao descumprimento parcial ou total de cláusulas contratuais por parte da contratada. Há uma reflexão constante sobre as não conformidades ao contrato para definir ações englobando as devidas correções. Compete à administração pública acompanhar e fiscalizar os contratos, observando 
direitos, obrigações e responsabilidade das partes, sob os ditames legais. ${ }^{24}$ Para tanto, os gestores afirmaram envidar esforços na comunicação intensa e efetiva para resolver as falhas, priorizando a satisfação dos usuários.

Outro exemplo de situações que levam à reflexão-na-ação dos gestores é a busca de opiniões e auxílio de outros colegas, quando a reflexão individual sobre as tentativas malsucedidas de eliminação das não conformidades não ajudam a enxergar o que saiu de errado em suas ações. Isso acontece por meio de reuniões administrativas e com a equipe.

Quando os gestores foram levados a refletir sobre as habilidades/ competências que um gestor de um RU/ serviço de alimentação deve dominar, foi apontado por eles que é de fundamental importância a junção dos conhecimentos técnicos e gerenciais. Contudo, a teoria é percebida como coadjuvante se comparada à prática profissional, quando se afirma que as ações práticas dos gestores de serviços de alimentação de coletividades possuem componentes teóricos que vez por outra despontam nas práticas administrativas. ${ }^{6}$ Ainda segundo os autores, o desafio de todo gestor é incorporar elementos teóricos, transformando o ambiente organizacional e sendo capaz de produzir novos resultados. ${ }^{6}$

Retomam-se as premissas de Donald Schön: a prática reflexiva se integraliza na reflexão sobre a reflexão-na-ação, ${ }^{10}$ representadas neste estudo, como a compreensão dos fatos, correção dos erros e avaliação dos resultados pelos gestores dos RUs durante o agir profissional. Para tanto, os gestores foram questionados sobre as "zonas indeterminadas" da gestão, ou seja, como eles agem em momentos imprevisíveis ou situações novas que fogem do planejamento e/ou da rotina diária.

As situações imprevistas e obscuras foram refletidas e citadas pelos gestores como sendo: falhas durante o processo de produção das refeições (ex.: problemas na infraestrutura, equipamentos, abastecimento de água e energia elétrica); oscilações do quantitativo de refeições (previsão da produção prejudicada); acidentes de trabalho (a falta de conhecimento na área de primeirossocorros e segurança do trabalho); desvio de produtos por parte dos funcionários e direitos trabalhistas (falta conhecimento dos procedimentos legais); imprevistos que ocorrem quando o alimento estraga e tem que ser substituído de última hora, ou o fornecedor entrega a matéria-prima em condições inadequadas, ou até quando ocorrem falhas pelo manipulador durante o preparo.

Merece atenção a falta do traquejo político dos gestores, pois é um hiato na gestão dos RUs. É característica ligada ao poder e à autoridade, portanto, e as pessoas não se sentem à vontade para falar. Mas de fato existe o recuo por parte dos gestores, deixando o lado técnico sobressair. Para fins de esclarecimento, é válido ressaltar, o histórico da gestão universitária que teve início em 1968, em pleno regime autoritário, quando se buscou integrar a universidade ao processo de desenvolvimento, com a modernização das universidades. Adiante, com a redemocratização do país nos governos vindouros, houve uma busca descontrolada por autonomia, e ocorreram diversos conflitos de determinadas linhas políticas entre os próprios membros da comunidade universitária. ${ }^{8}$ 
Tal histórico converge para as dificuldades dos gestores frente à dimensão política da gestão universitária, em lidar com propostas diferenciadas de vários segmentos (colegiados, gestores, pró-reitores, técnicos administrativos, docentes, estudantes, movimentos estudantis, sindicatos etc.). Há ainda as restrições burocráticas, alertando para a existência de um modelo político no contexto da administração universitária utilizando teorias de conflito, do poder nas comunidades acadêmicas e de grupos de interesse. ${ }^{8,16}$

Nesse contexto, a despeito da fala de um dos entrevistados, o RU é visto como "marketing" da universidade. Sobre isso, alguns autores descrevem que o marketing nos serviços de alimentação que não possuem fins lucrativos, como os RUs, equivale ao lucro das empresas privadas e é evidenciado por meio da satisfação e fidelização do cliente.$^{25}$ Neste sentido, envolve a qualidade do produto final, marca e preço. Nos serviços de alimentação, o produto é a refeição ou a preparação vendida; e este é sempre acompanhado de um serviço - que no caso, é o modo como a refeição ou preparação é oferecida, acrescentando-se atributos como sobremesa inclusa, café na saída etc., além do objetivo de venda. ${ }^{25} \mathrm{~A}$ alta gestão das universidades pressiona os gestores dos RUs nesse sentido, para fazer do RU local de "barganha".

Quanto à avaliação das ações, observou-se que a maioria dos profissionais engradece a reflexão crítica, mas nem sempre eles têm tempo de parar, avaliar e reavaliar suas ações. Acham necessário realizá-la a fim de saber como agir e não repetir os mesmos erros, ou encontrar onde aconteceu a falha, para a devida correção. Os gestores afirmaram também que a usam para embasar as tomadas de decisão e os planejamentos, assim como para o crescimento, realização humana e profissional.

De um modo geral, o refletir-na-ação expôs a limitação de autonomia dos gestores, por estarem atrelados a decisões de instâncias superiores: pró-reitoria e reitoria (contratantes) e diretoria da empresa e contratante (contratadas). Como o RU funciona como atividade-meio, não há um olhar direto da alta gestão para os problemas; eles se tornam pontuais em meio às reivindicações dos usuários quando estão insatisfeitos; e do ponto de vista intersetorial; a tomada de decisão e, consequentemente, a ação esbarram na burocracia.

\section{Conclusões}

A prática reflexiva dos gestores foi concebida a partir da identificação das principais dificuldades de gestão dos RUs, utilizando a maneira particular e profissional de ver a realidade e construí-la da forma como a veem. Quando os gestores responderam aos questionamentos e apontaram os obstáculos, as ações e a ausência das ações, através de uma conversação reflexiva com as situações práticas, eles revelaram os processos tácitos de construção de uma visão de mundo em que alicerçam toda sua prática. 
Indo além nas considerações acerca da associação da prática reflexiva com a prática profissional aplicada ao contexto da gestão dos RUs, têm-se as ações, frente aos problemas, imprevistos e limites (realidade do ambiente organizacional). Retorna-se a reflexão-na-ação quanto às habilidades/ competências necessárias e desenvolvidas para estas ações, inclusive nas situações obscuras e/ou indeterminadas da prática profissional. Dentre estas se identificaram, além dos imprevistos que ocorrem na gestão da produção, a dimensão política inserida na gestão dos RUs, com ações e conflitos inerentes.

As mudanças de paradigmas na gestão de serviços de alimentação, principalmente nas práticas dos gestores subjacentes à reflexão de seus hábitos e ações profissionais, ou seja, na percepção, compreensão e interpretação das ações e resultados para um entendimento detalhado sobre esses aspectos que ainda não foram construídos. Além disso, vale mencionar a importância de uma perspectiva baseada em práticas, constituindo um modo de adquirir conhecimento em ação, construindo-o a partir de um contexto de interação.

Portanto, a prática reflexiva no campo da gestão dos RUs tem o intuito de evidenciar suas possíveis contribuições ao contexto da gestão institucional. Sabe-se que ainda há muito a ser trabalhado, do ponto de vista teórico e empírico, mas a junção desses dois temas pressupõe um potencial enriquecimento e estímulo.

A prática reflexiva propõe-se a promover evolução e inovação a partir da ação, através da tomada de consciência que envolve uma observação distanciada. Pode apresentar pontos iniciais para futuros estudos e mesmo para iniciativas de praticantes no âmbito da utilização da prática reflexiva em contextos de gestão de serviços de alimentação terceirizados inseridos nas instituições.

\section{Colaboradores}

Cardoso CIXS participou de todas as etapas, desde a concepção do estudo até a revisão da versão final do artigo; Calazans DLMS participou do desenho do estudo, da análise e interpretação dos dados, da redação e da versão final; Feitosa MGG orientou todas as fases do estudo - concepção, análise e interpretação dos dados e revisão final.

Conflito de Interesses: os autores declaram não haver conflito de interesse.

\section{Referências}

1. Abreu ES, Spinelli MGN, Pinto AMS. Gestão de Unidades de Alimentação e Nutrição: um modo de fazer. 3 ed. São Paulo: Metha; 2009.

2. Colares LGT. Contratação de serviços terceirizados de alimentação e nutrição: orientações técnicas. Rio de Janeiro: Rubio; 2014. 
3. Nóbrega ABN. Competências gerenciais do nutricionista em unidades de alimentação e nutrição terceirizadas em Natal - RN [dissertação]. [Natal]: Universidade Potiguar, Pós-Graduação em Administração; 2011.

4. Brasil. Presidência da República. Casa Civil. Decreto n ${ }^{\circ}$ 7.234, de 19 de julho de 2010. Dispõe sobre o Programa Nacional de Assistência Estudantil - PNAES. Diário Oficial da União. 20 jul. 2010; 1:5.

5. Brasil. Lei n̊ 8.234, de 17 de setembro de 1991. Regulamenta a profissão de Nutricionista e determina outras providências. Diário Oficial da União. 17 set. 1991.

6. Aguiar OB, Kraemer FB, Menezes MFG. Gestão de pessoas em unidades de alimentação e nutrição. Rio de Janeiro: Rubio; 2013.

7. Rosa COB, Monteiro MRP. Unidades produtoras de refeições: uma visão prática. Rio de Janeiro: Rubio; 2014.

8. Hardy C, Fachin R. Gestão estratégica na universidade brasileira: teoria e casos. 2 ed. Porto Alegre: Editora UFRGS; 2000.

9. Reis GG, Silva LM, Eboli MP. A prática reflexiva e suas contribuições para a educação corporativa. Revista de Gestão-REGE/ FEA/USP. 2010; 17(4):403-419.

10. Schön DA. Educando o profissional reflexivo: um novo design para o ensino e a aprendizagem. Porto Alegre: Artmed; 2000.

11. 11 Perriton L, Hodgson V. Positioning theory and practice question(s) within the field of management learning. Management Learning. 2013; 44(2):144-160.

12. Sofo F, Yeo R, Villafañe J. Optimizing the learning in action learning: reflective questions, levels of learning, and coaching. Advances in Developing Human Resources. 2010; 12(2):205-224.

13. Isosaki M, Cardoso E, Perazzolo E, Omaki CN. Liderança para gestores de nutrição. São Paulo: Atheneu; 2012.

14. Kerch AL. O desenvolvimento dos 'talentos artísticos profissionais' de estudantes de administração nas atividades de empresas juniors [Dissertação]. [Porto Alegre]: Universidade Federal do Rio Grande do Sul, Programa de Pós-graduação em Administração; 2013.

15. Mattos PLCL. Análise de entrevistas não estruturadas: da formalização à pragmática da linguagem. In: Godoi CK, Bandeira-de-Mello R, Silva AB, organizadores. Pesquisa qualitativa em estudos organizacionais: paradigmas, estratégias e métodos. 2 ed. São Paulo: Saraiva; 2006.

16. Campos RC; Silva KAT. Gênero e empoderamento: um estudo sobre mulheres gerentes nas universidades. Anais do XXXVIII Encontro da Associação Nacional de Pós-Graduação e Pesquisa em Administração - ENANPAD; 13-17 set. 2014; Rio de Janeiro.

17. Barbosa MAC, Mendonça JRC. O professor-gestor em universidades federais: alguns apontamentos e reflexões. Anais do XIII Coloquio de Gestión Universitaria en Américas; 27-29 nov. 2013; Buenos Aires.

18. Paranaguá MMM. Gestão de pessoas na área de atuação de alimentação coletiva. In: Rosa COB, Monteiro MRP, organizadores. Unidades produtoras de Refeições: uma visão prática. Rio de Janeiro: Rubio; 2014. 
19. Querino RA. Restaurante universitário: desafios e práticas exitosas. Fórum Nacional de Pró-Reitores de Assuntos Comunitários e Estudantis (FONAPRACE); 2013; Cuiabá.

20. Maia TML. Planejamento e gestão estratégica para o restaurante universitário da UFC em um cenário de expansão do número de alunos [Dissertação]. [Fortaleza]: Universidade Federal do Ceará, Programa de Pós-Graduação em Políticas Públicas e Gestão da Educação Superior; 2008.

21. Braga AC, Pereira TL, Andrade Junior PP. Avaliação de restaurante universitário por meio de indicadores de qualidade. Desenvolvimento em Questão. 2015; 13(30):306-326.

22. Moraes PRS. Terceirização e precarização do trabalho humano. Rev. TST. 2008; 74(4):148-168.

23. Alevato H, Araújo EMG. Gestão, organização e condições de trabalho em uma Unidade de Alimentação e Nutrição. V Congresso Nacional de Excelência em Gestão: Gestão do Conhecimento para a sustentabilidade; 2-4 jul. 2009; Niterói.

24. Suñe C, Castro EB, Magalhães ACM. Contratos administrativos na esfera pública: uma análise do papel do gestor e do fiscal. IX Congresso Nacional de Excelência em Gestão: gestão do conhecimento para a sustentabilidade; 2013; Niterói.

25. Balchiunas D. Gestão de UAN: um resgate do binômio alimentação e nutrição. São Paulo: Roca; 2014.

Recebido: 13 de outubro, 2017

Revisado: 07 de março, 2018

Aceito: 21 de março, 2018 